A. Flöel

Klinik für Neurologie, Universitätsmedizin Greifswald, Greifswald, Deutschland

\title{
Erratum zu: INTREPAD (,investigation of naproxen treatment effects in presymptomatic Alzheimer disease")
}

\author{
Naproxen zur Verlangsamung der Progression der präsymptomatischen \\ Alzheimer-Krankheit
}

\section{Erratum zu:}

DGNeurologie 2020

https://doi.org/10.1007/s42451-020-00162-0

Der Artikel „INTREPAD (,investigation of naproxen treatment effects in presymptomatic Alzheimer disease ")“ von Flöel, A. wurde ursprünglich Online First ohne „Open Access" auf der Internetplattform des Verlags publiziert. Nach der Veröffentlichung in Band 3 Heft 3 pp. 252-253 hatten sich die Autoren für eine „Open Access“-Veröffentlichung entschieden. Das Urheberrecht des Artikels wurde deshalb in (c) Der/die Autor(en) 2020 geändert. Dieser Artikel ist jetzt unter der Creative Commons Namensnennung 4.0 International Lizenz veröffentlicht, welche die Nutzung, Vervielfältigung, Bearbeitung, Verbreitung und Wiedergabe in jeglichem Medium und Format erlaubt, sofern Sie den/die ursprünglichen Autor(en) und die Quelle ordnungsgemäß nennen, einen Link zur Creative Commons Lizenz beifügen und angeben, ob Änderungen vorgenommen wurden.

Die in diesem Artikel enthaltenen Bilder und sonstiges Drittmaterial unterliegen ebenfalls der genannten Creative Commons Lizenz, sofern sich aus der Abbildungslegende nichts anderes ergibt. Sofern das betreffende Material nicht unter der genannten Creative Commons Lizenz steht und die betreffende Handlung nicht nach gesetzlichen Vorschriften erlaubt ist, ist für die oben aufgeführten Weiterverwendungen des Materials die Einwilligung des jeweiligen Rechteinhabers einzuholen.

Weitere Details zur Lizenz entnehmen Sie bitte der Lizenzinformation auf http://creativecommons.org/licenses/by/4.0/ deed.de.

\section{Korrespondenzadresse}

Prof. Dr. A. Flöel

Klinik für Neurologie

Universitätsmedizin Greifswald

Ferdinand-Sauerbruch-Straße, 17475 Greifswald,

Deutschland

agnes.floeel@med.uni-greifswald.de

Open Access. Dieser Artikel wird unter der Creative Commons Namensnennung 4.0 International Lizenz veröffentlicht, welche die Nutzung, Vervielfältigung, Bearbeitung, Verbreitung und Wiedergabe in jeglichem Medium und Format erlaubt, sofern Sie den/die ursprünglichen Autor(en) und die Quelle ordnungsgemäß nennen, einen Link zur Creative Commons Lizenz beifügen und angeben, ob Änderungen vorgenommen wurden.

Die in diesem Artikel enthaltenen Bilder und sonstiges Drittmaterial unterliegen ebenfalls der genannten Creative Commons Lizenz, sofern sich aus der Abbildungslegende nichts anderes ergibt. Sofern das betreffende Material nicht unter der genannten Creative Commons Lizenz steht und die betreffende Handlung nicht nach gesetzlichen Vorschriften erlaubt ist, ist für die oben aufgeführten Weiterverwendungen des Materials die Einwilligung des jeweiligen Rechteinhabers einzuholen.

Weitere Details zur Lizenz entnehmen Sie bitte der Lizenzinformation auf http://creativecommons.org/licenses/by/4.0/deed.de.

Funding. Open Access funding enabled and organized by Projekt DEAL

Die Online-Version des Originalartikels ist unter https://doi.org/10 1007/s42451-020-00162-0zu finden. 